\title{
Virtual Design and Dynamic Simulation of Valve Trains
}

\author{
Guantao Xuan ${ }^{1,2}$ and Yuanyuan Shao ${ }^{1, a}$ \\ ${ }^{1}$ College of Mechanical and Electronic Engineering, Shandong Agricultural University, 271018 Tai'an, China \\ ${ }^{2}$ Shandong Province Key Laboratory of Horticultural Machinery and Equipment, 271018 Tai'an, China
}

\begin{abstract}
The valve train plays an important role in the engine, which has a great influence on engine performance and reliability. In this paper, valve trains are studied based on multi-body dynamics theory and virtual prototype technology. Multi-rigid-body dynamic model of the valve train is established with Adams software, and then simulation and calculation are carried out. Dynamic characteristics of the valve train are obtained including force and motion of each component. The research results have important theoretical significance and practical engineering value in the design, dynamic analysis and optimization of valve trains.
\end{abstract}

\section{Introduction}

The valve train in an internal combustion engine is responsible for controlling the air/fuel mixture into the cylinder during intake and to allow the exhaust gases to exit after combustion [1].It carries out complicated and heavy working, and suffers intense vibration and shock [2]. Operating these engines in high speed usually causes some dynamic problems such as spring surge, friction and fatigue damage, valve bounce, lifter/cam pair separation, etc. So it is important for engines to improve the valve train's design quality. Traditionally, valve trains are designed by project comparison and tests, which are waste of time and delay the research period. The valve train is also designed as an elastic dynamic system, but it is calculated complicatedly and not demonstrated clearly [3-6]. With the development of computer, CAE simulation technology is more and more applied to design the valve train and predict its characteristics, such as finite element analysis, CFD and Adams software [7-11].

In this paper, applying multi-body dynamics theory and virtual prototype technology, the multibody dynamic model of the valve train is established with Adams software, and simulation is carried out by using the virtual prototype technology. The dynamics of components are obtained such as the lift, velocity, acceleration of valve, the contact stress between cam and lifter. The results show that the simulation of the valve train is feasible during the initial developing stage without physical prototype.

\section{Multi-body dynamic equation of valve trains}

Valve trains typically are composed of camshafts, lifters, pushrods, rocker arms, valves and valve springs. Therefore, the valve train can be considered as a multi-body system composed of many parts, and its analysis is carried out by using the multi-body dynamics theory. Using the Lagrange equation as the multi-body dynamic analysis method, dynamic equation of the valve train is established. Every

\footnotetext{
${ }^{\mathrm{a}}$ Corresponding author : xoyo111@163.com
} 
rigid-body $i$ of the valve train is described with six generalized coordinates as shown in equation (1), which are Cartesian coordinates of mass center in the inertial reference frame and Euler angles reflecting azimuth of the rigid-body.

$$
q_{i}=[x, y, z, \phi, \theta, \varphi]_{i}^{T}, \quad q=\left[q_{1}^{T}, \ldots \ldots q_{n}^{T}\right]^{T}
$$

And differential equation of the valve train motion is also established as in (2) with lagrangian multiplier method.

$$
\frac{d}{d t}\left(\frac{\partial T}{\partial \dot{q}}\right)^{T}-\left(\frac{\partial T}{\partial q}\right)^{T}+\varphi_{q}^{T} \rho+\theta_{q}^{T} \mu-Q=0
$$

Integrity constraint equation is defined as follows.

$$
\varphi(q, t)=0
$$

Non-holonomic constraint equation is generated as follows.

$$
\theta(q, \dot{q}, t)=0
$$

Where, $T$ is system energy, $q$ is generalized coordinates array, $Q$ is generalized force array, $\rho$ is lagrangian multiplier array for integrity constraint equations, and $\mu$ is lagrangian multiplier array for non-holonomic constraint.

\section{Multi-body dynamic model}

The geometric model of the valve train is established by using multi-body dynamics software Adams/engine, and then the constraint, drive and load are defined as shown in Table 1 and Table 2. Finally, the multi-rigid body dynamic model of the valve train is established as shown in Figure 1.

Table 1. Component parameters

\begin{tabular}{|c|c|c|c|c|c|}
\hline \multirow{2}{*}{ Symbol } & \multirow{2}{*}{ component } & \multirow{2}{*}{$\begin{array}{c}\text { Quality } \\
(\mathbf{K g})\end{array}$} & \multicolumn{3}{|c|}{ Rotary inertia(Kg·mm2) } \\
\cline { 4 - 6 } & & Ixx & Iyy & Izz \\
\hline A1 & Cam & 0.1688 & 22.6021 & 30.9096 & 49.4604 \\
\hline A2 & Cam Shaft & 0.221 & 50.640 & 46.560 & 28.812 \\
\hline A3 & Valve & 4.2708 & 43.5432 & 43.5432 & 1.8958 \\
\hline A4 & Spring Seat & 1.8821 & 1.2187 & 1.2187 & 2.4091 \\
\hline
\end{tabular}

Table 2. Main constraints

\begin{tabular}{|c|c|c|}
\hline Symbol & Object & Constraint \\
\hline B1 & Cam and Ground & Revolute joints \\
\hline B2 & Cam Shaft and Cam & Fixed Joints \\
\hline B3 & Cam and Lifter & Contact Joints \\
\hline B4 & Valve and Ground & Cylinder Joints \\
\hline B5 & Valve and Ground & Collision Constraint \\
\hline B6 & Valve and Spring Seat & Fixed Joints \\
\hline
\end{tabular}




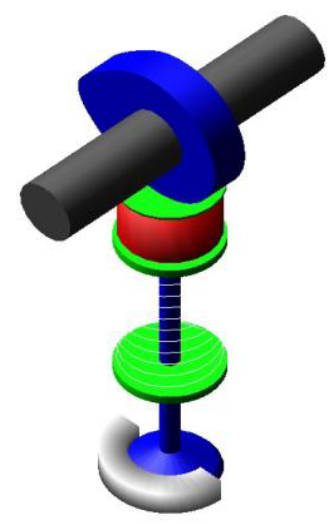

Figure 1. Multi-body dynamic model

\section{Dynamic simulation and analysis}

After establishing the virtual prototype model of the valve train, a rotary drive is applied to the camshaft to simulate the actual motion. When the engine works at the rated speed $3000 \mathrm{r} / \mathrm{min}$, multibody dynamic simulation of the valve train is carried out, and the camshaft, cam, valve, valve springs, and valve performance are obtained and analyzed.

\subsection{Force between cam and lifter}

In valve trains, the contact force between cam and lifter is very lager, and is prone to premature wear or scratch, split and other faults. From Figure 2, it can be seen that the maximum force between cam and lifter is $3740 \mathrm{~N}$. This impact force will do harm to the valve train and engine if it can't be controlled properly.

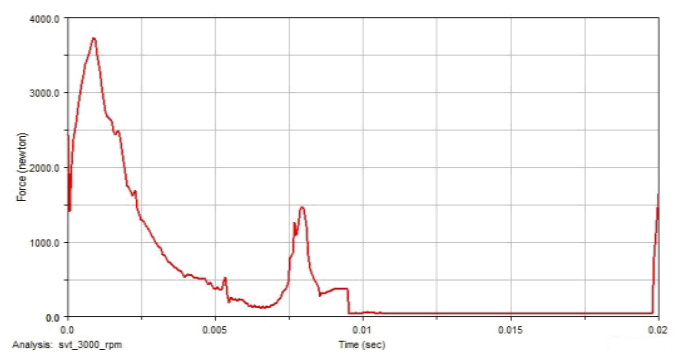

Figure 2. Force between cam and lifter

\subsection{The valve seating force}

In valve trains, the valve is suffering continuous impact from the valve seating force under no lubrication. The friction and abrasion caused by the valve seating force are important reasons for the failure of the valve train to work. Figure 3 shows the maximum valve seating force is $2600 \mathrm{~N}$, which is caused by burst pressure of valve as shown in Figure 4 . 


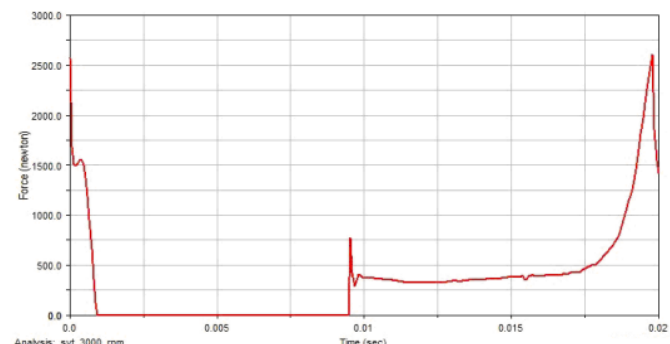

Figure 3. The valve seating force

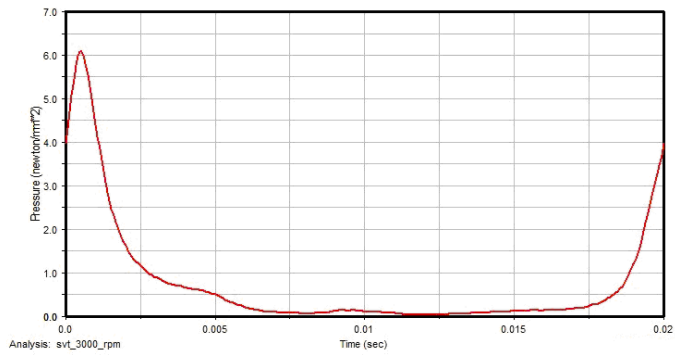

Figure 4. Pressure of valve

\subsection{Motion of valve}

Motion of valve is generated as shown in Figure 5 and Figure 6, and some conclusions can be drawn: at rated camshaft speed $3000 \mathrm{r} / \mathrm{min}$, valve lift is about $8.5 \mathrm{~mm}$, and the maximum velocity of valve is $3540 \mathrm{~mm} / \mathrm{s}$. Through Adams simulation, a variety of force and kinematic parameters are provided for the further finite element analysis. These data can also be compared with experimental data in order to further optimize the model.

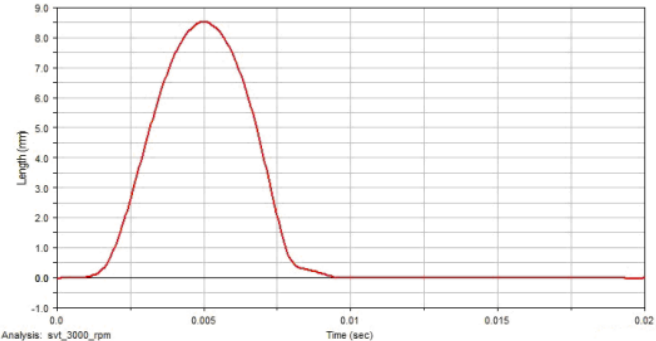

Figure 5. Valve lift

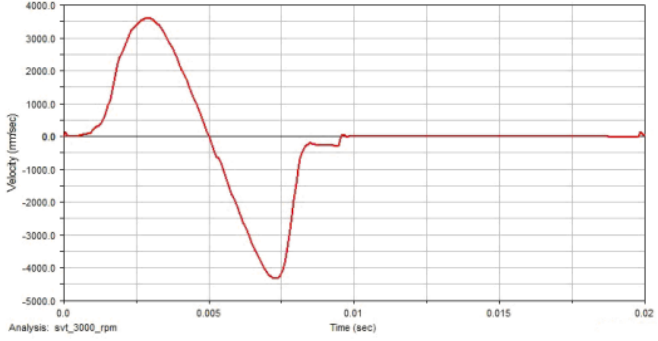

Figure 6. Velocity of valve

\subsection{Acceleration analysis of valve}

Valve acceleration is an important dynamic parameter of valve trains. There is a great acceleration impact at the moment of valve opening and seat, and the impact should be reduced as much as possible. In the cam profile design process, the positive peak acceleration and reverse peak acceleration are often used as constraints to control the cam contact stress and prevent the valve movement of valve trains. In this section, the valve acceleration is taken as the analysis object, and the following are the acceleration curves of the valve under different camshaft speeds.

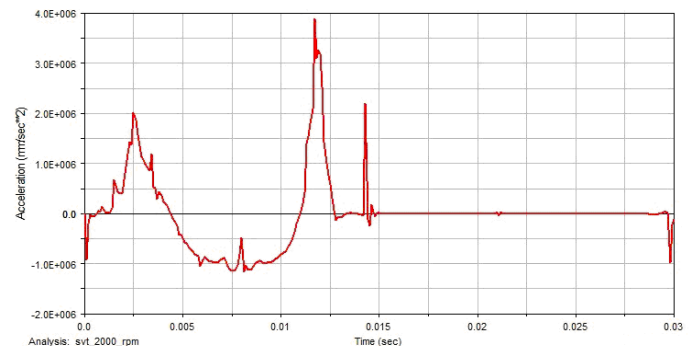

(a) at the rated camshaft speed $2000 \mathrm{r} / \mathrm{min}$

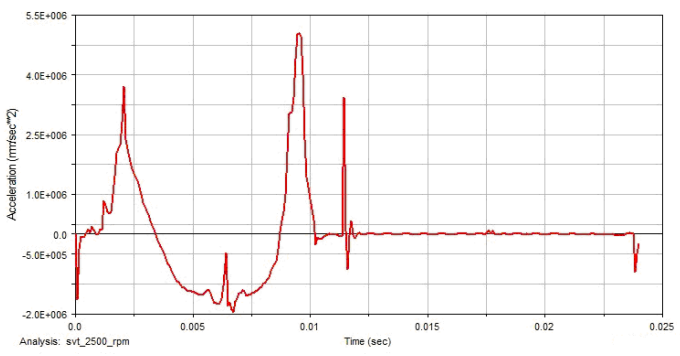

(b) at the rated camshaft speed $2500 \mathrm{r} / \mathrm{min}$ 


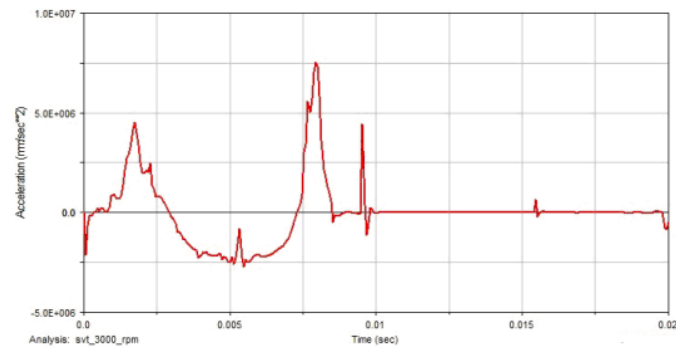

(c) at the rated camshaft speed 3000r/min

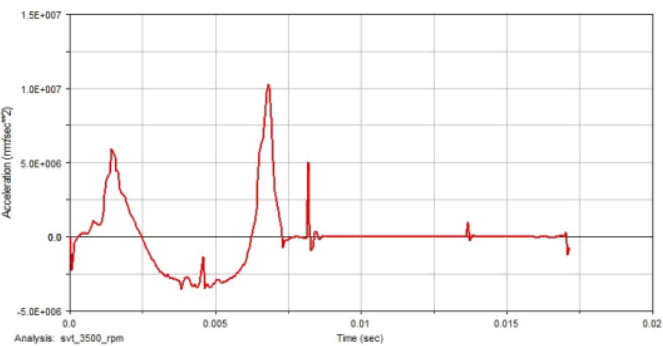

(d) at the rated camshaft speed $3500 \mathrm{r} / \mathrm{min}$

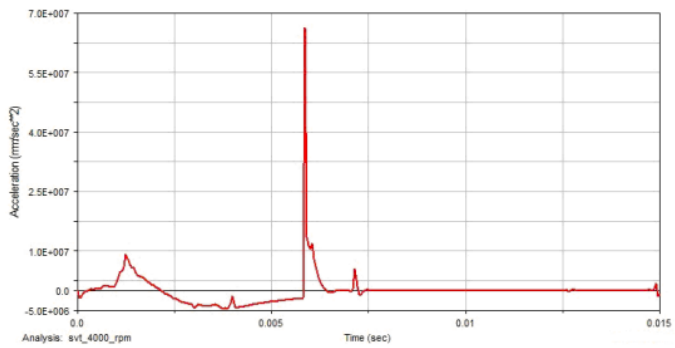

(e) at the rated camshaft speed $4000 \mathrm{r} / \mathrm{min}$

Figure 7. Acceleration of valve under different camshaft speeds

Some analysis conclusions are drawn from Figure 7 (a) - (e). With the increase of camshaft speed, valve acceleration is more and more high, which brings greater impact force to valve and has a great influence on engine operating characteristics. There is acceleration vibration of the valve at different camshaft speeds. But the valve vibration is weak at low speed, and there is obvious vibration at high speed. The negative acceleration width is one of the important indexes in the design of the cam profile. The greater the width is, the longer the valve opening time is and the larger time-area value is. As can be seen from the Figure 7, negative acceleration section of valve is wide at low speed. With increasing speed, negative valve acceleration section becomes gradually narrow. It shows engine can obtain higher time-area value in the low speed stage, and the time-area value is relatively low in the high speed stage due to the work cycle time shortened.

\section{Conclusions}

In this study, it is concluded that the valve train model is established well using multi-body dynamics theory, and dynamic response of the valve train can be analysed truly by simulation with Adams software. It is considered that the dynamic analysis of the valve train by using the virtual prototype technology is an important method for the modern design of valve trains.

\section{Acknowledgments}

We would like to thank "National Natural Science Foundation of China (31671632)", "Natural Science Foundation of Shandong Province (BS2015NY012)" and "Key Research and Development Program of Shandong Province (2016GNC112007)" for financial supports.

\section{References}

1. C. F. Taylor, The Internal-Combustion Engine in Theory and Practice (The M.I.T.Press, 1985) 
2. Simon K. Chen, Advanced Cylinder Head, Valve Train, Combustion and Fuel Systems for High Power-Density Truck Diesel Engines, Alternative Fuels and Heavy Duty Engines, 1247(1997)

3. Rohde S M, Whicker D, and Browne A L, Dynamic Analysis of Elasto-Hydrodynamic Squeeze Films, ASME Journal of Lubrication Technology 98, 3(1976)

4. H. Sakai And K. Tsuda, Analysis of valve motion in overhead valve linkages, Bulletin of the JSME 13, 55(1970)

5. A. P. Pisano, and F. Freudenstein, An experimental and analysis investigation of the dynamic response of a high-speed cam-follower system, Part 1:Experimental Investigation, ASME J. of Mechanisms, Transactions, and Automation in Design 105, 12(1983)

6. Zuomin Liu, and Childs THC, Material dissipative in automatic engine exhaust valve-seat wear dissipative processes in tribology, Tribology Series, 27(1994)

7. Liu H, and Kim D, Effects of end coils on the natural frequency of automotive engine valve springs, International Journal of Automotive Technology 10, 4(2009)

8. Cardona A, and Geradin M, Kinematical and dynamic analysis of mechanical with Cams, Computer Methods in Applied Mechanics and Engineering 103, 2(1993)

9. Qin Wen-jie, Liao Ri-dong, Zuo Zheng-xing, and Liang Li-wei, Applying multibody system dynamics to the improvement of valve train's cam profiles, Journal of Beijing Institute of Technolog 11, 2(2002)

10. E. Sher, and T. Bar-Kohany, Optimization of variable valve timing for maximizing performance of an unthrottled SI engine-a theoretical study, Energy, 27(2002)

11. J.Lampinen, Cam shape optimization by genetic algorithm, Computer-Aided Design, 35 (2003) 